\title{
Detailed Modeling of Solar Inverter
}

\author{
Nezihe Yıldıran \\ Bahcesehir University \\ Besiktas, Istanbul, Turkey \\ kucukne@yahoo.com
}

\begin{abstract}
This paper presents the analysis and simulation of grid connected solar inverter. The system is composed of a solar panel, DC-DC boost converter, and three phase DC-AC voltage source inverter. To analyze the model, MATLAB system function (S-function) feature is used. S-function is chosen to obtain the system discrete and applicable model in real system to be able to use in an embedded system. The system mathematical equations are developed and some necessary equations are converted to discrete form to be able to adapt to system function (S-function). The system detailed model is developed and simulated by using MATLAB S-function feature. Simulated results are presented.
\end{abstract}

Keywords: Grid connection, boost converter, solar inverter, modeling, Matlab, S-function

\section{Introduction}

Nowadays, smart grid and microgrid terms have gained importance for the reliable integration of distributed energy resources, including energy storage systems, power electronic converters, controllable loads, monitoring and protection devices, and providing islanding operation during outages. Key point of the new grid is distributed energy sources. Solar energy is the one of the major distributed energy sources. It is reliable, limitless, and non-polluting source.

Building solar energy conversion system is very hard because there are many different and complex components in the power system. Hence, many researchers have been trying to develop accurate simulation model with different tools. Matlab is one of the important simulation software. It has ready blocks and user defined blocks for simulation. In this paper, user defined block is used to obtain an adequate simulation model which is valid for real systems [1]. Matlab S-function feature provides codes which can be used in embedded systems with small changes. Furthermore, entire system parameters can be taken into account. Most of the ready blocks in simulation programs neglect some parameters or they take some parameters ideally. The system simulation model which constructed in S-function is closer to the real system than ready blocks results.

\section{Solar Cell}

Elementary part of the photovoltaic (PV) device is photovoltaic cell and it converts exposed sunlight to electricity. Cells can be connected to suitable loads directly. Without any moving parts inside the PV device, their lifetime is more than 25 years. On the other hand, power generation capability may be reduced to $75-80 \%$ of nominal ratings because of ageing [2].

\section{Practical PV Cell Model}

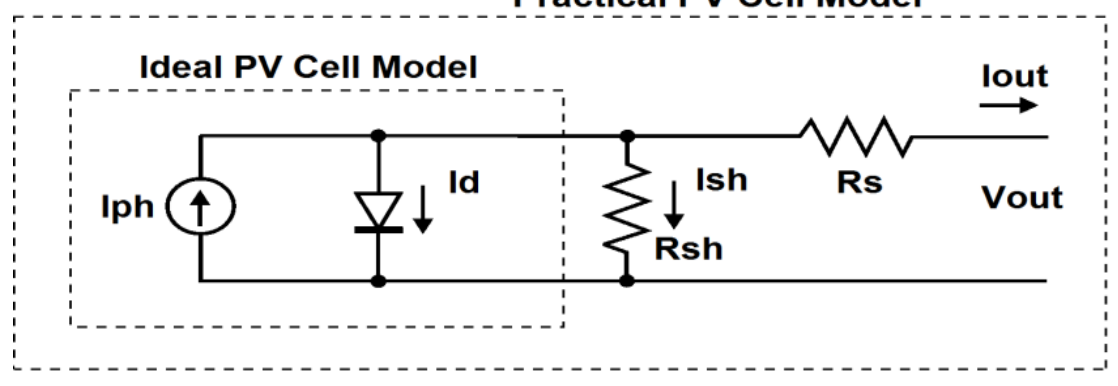

Fig. 1: Equivalent circuit of solar cell. 
Single diode equivalent circuit of solar cell in ideal and practical case is given in Fig. 1. In this paper, practical solar cell model is used.

Output current equation of the equivalent circuit is $[3,4]$ :

$$
\begin{gathered}
I_{\text {out }}=I_{p h}-I_{\text {sat }} \cdot\left(\exp \left(\frac{q \cdot(\text { Vout }+ \text { Rs. Iout })}{A \cdot k \cdot T}\right)-1\right)-\frac{(\text { Vout }+ \text { Rs. Iout })}{\text { Rsh }} \\
I_{p h}=\left[I_{s c}+K_{I} \cdot\left(T-T_{r}\right)\right] \cdot \frac{G}{G_{n}} \\
I_{s a t}=I_{r r} \cdot\left(\frac{T}{T_{r}}\right)^{3} \cdot \exp \left\{\frac{q \cdot E_{\text {gap }}}{k \cdot A}\left(\frac{1}{T_{r}}-\frac{1}{T}\right)\right\} \\
I_{r r}=\frac{I_{s c}}{\left(\exp \left(\frac{q \cdot V_{o c}}{N_{s} \cdot A \cdot k \cdot T}\right)-1\right)}
\end{gathered}
$$

$I_{p h}$ is photocurrent source; $I_{s a t}$ is module reverse saturation current; A is ideality factor; $k$ is Boltzman constant $\left(1,3806503.10^{-23} \mathrm{j} /{ }^{\circ} \mathrm{K}\right)$; $\mathrm{T}$ is surface temperature of the solar cell; $\mathrm{R}_{\mathrm{s}}$ is series resistance; $\mathrm{R}_{\mathrm{sh}}$ is parallel resitance; $\mathrm{I}_{\mathrm{sc}}$ is short circuit current; $K_{I}$ is temperature coefficient of open circuit voltage; $T_{r}$ is reference temperature of the solar cell; $G$ is solar irradiation on the device surface; $G_{n}$ is nominal irradiation; $I_{\text {sat }}$ is module reverse saturation current; $I_{\mathrm{rr}}$ is reverse saturation current at a reference temperature and solar irradiation; $E_{\text {gap }}$ is energy of the band gap; $q$ is electron charge $\left(1,60217646.10^{-}\right.$ ${ }^{19 \circ} \mathrm{C}$ ); $\mathrm{V}_{\text {oc }}$ is open circuit voltage and $\mathrm{N}_{\mathrm{s}}$ is number of cells connected in series.

To solve Eq. (1), some parameters $\left(\mathrm{V}_{\mathrm{sc}}, \mathrm{I}_{\mathrm{sc}}, \mathrm{V}_{\mathrm{mp}}, \mathrm{I}_{\mathrm{mp}}\right.$, and $\left.\mathrm{K}_{\mathrm{I}}\right)$ can be found from datasheet of solar cell or panel, $\mathrm{I}_{\mathrm{sat}}$, $\mathrm{I}_{\mathrm{ph}}$, and $\mathrm{I}_{\mathrm{rr}}$ can be calculated from Eq. (2), (3), and (4), A and $\mathrm{E}_{\mathrm{gap}}$ can be defined according to material of the cell. $R_{\mathrm{s}}$ and $R_{\mathrm{sh}}$ remain as unknown. To find resistance values, maximum power point can be used. Maximum power point is defined as the operating point at which the power has maximum value across the load. The calculated maximum power in the simulation $\left(\mathrm{P}_{\max , \mathrm{m}}\right)$ is equal to the maximum experimental power $\left(\mathrm{P}_{\max , \mathrm{e}}\right)$ from the datasheet at the maximum power point. Initial values of the resistances are taken as zero and $P_{\max , m}$ is calculated. If the difference between $P_{\max , m}$ and $P_{\max , e}$ is bigger than error, $R_{s}$ is increased and $R_{s h}$ is calculated by (6). If the difference between $P_{\text {max,m }}$ and $P_{\max , e}$ is smaller than error, $R_{s}$ and $R_{s h}$ are found.

$$
\begin{aligned}
P_{\text {max }, m} & =V_{m p} \cdot I_{m p}=V_{m p} \cdot\left[I_{p h}-I_{s a t} \cdot\left(\exp \left(\frac{q \cdot(V m p+R s \cdot I m p)}{N_{s} \cdot A \cdot k \cdot T}\right)-1\right)-\frac{(V m p+R s \cdot I m p)}{R s h}\right]=P_{\text {max }, e} \\
R_{s h} & =V_{m p} \cdot(V m p+\text { Rs. Imp }) /\left\{V_{m p} \cdot I_{p h}-V_{m p} \cdot I_{s a t} \cdot\left(\exp \left(\frac{q \cdot(V m p+R s \cdot I m p)}{N_{s} \cdot A \cdot k \cdot T}\right)-1\right)-P_{\text {max }, e}\right\}
\end{aligned}
$$

To calculate output current equation in discrete form, equation was rewritten and solved with Newton-Raphson algorithm.

$$
I_{\text {out }}=\left(\frac{\left(I_{\text {ph }}+I_{\text {sat }}-\left(\frac{V_{\text {out }}}{R_{\text {sh }}}\right)\right)}{\left(1+\frac{R_{s}}{R_{s h}}\right)}\right)-\text { Lambert_func }\left[\frac{R_{S} \cdot I_{\text {sat }} \cdot \exp \left(\frac{V}{V_{t}}\right) \cdot \exp \left(\frac{I_{\text {ph }}+I_{\text {sat }}-\frac{V}{R_{s h}}}{V_{t} \cdot\left(1+\frac{R_{s}}{R_{s h}}\right)}\right) \cdot R_{S}}{V_{t} \cdot\left(1+\frac{R_{s}}{R_{s h}}\right)}\right] * V_{t} / R_{s}
$$

\section{Boost Converter}

The simplest controllable DC-DC converters are consisted of one inductor, one controlled semiconductor device, and one diode mainly. The input voltage of the converter is an unregulated DC source and the output of the converter has regulated DC voltage [5]. If the input side of the converter is PV system, the best efficiency can be obtained with the boost converter [6]. Boost converter converts lower and variable DC source to higher and constant DC voltage. 
Figure 2 shows schematic of boost converter and state space equations of the boost converter considering entire system parameters such as resistance of the input inductance, the resistance of the output capacitor, the mosfet voltage drop and on time resistance, and the diode voltage drop and on time resistance is given in this part [7].

$\mathrm{V}_{\mathrm{G}}$ is the input voltage; $\mathrm{L}$ shows the input inductance; $\mathrm{R}_{\mathrm{L}}$ is the resistance of the input inductance; $\mathrm{D}$ is the output diode in the figure; $R_{C}$ is the resistance of the output capacitor; $C$ is the output capacitor; $V_{M}$ is the mosfet voltage drop; $R_{M}$ is mosfet on time resistance; $\mathrm{V}_{\mathrm{D}}$ is the diode voltage drop; $\mathrm{R}_{\mathrm{D}}$ is the diode on time resistance; and $\mathrm{R}$ is the output load.

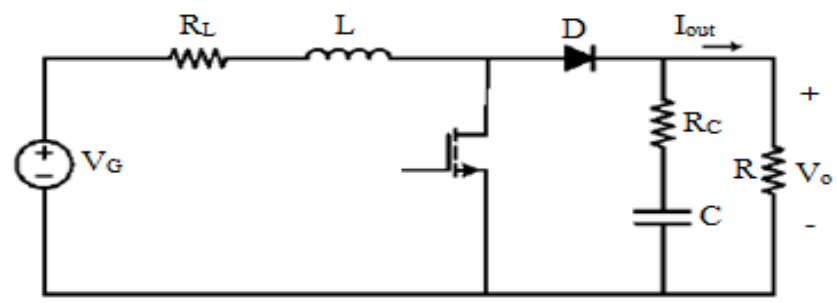

Fig. 2: Schematic of boost converter.

The equations of the converter when the switch is ON:

$$
\begin{aligned}
& \dot{x}=A_{\text {on }} \cdot x+B_{\text {on }} \cdot u \rightarrow\left[\begin{array}{l}
i_{L} \\
\dot{v}_{C}
\end{array}\right]=\left[\begin{array}{cc}
-\left(R_{L}+R_{M}\right) / L & 0 \\
0 & -1 /\left(R+R_{C}\right) \cdot C
\end{array}\right]\left[\begin{array}{c}
i_{L} \\
v_{C}
\end{array}\right]+\left[\begin{array}{ccc}
1 / L & -1 / L & 0 \\
0 & 0 & 0
\end{array}\right]\left[\begin{array}{l}
V_{G} \\
V_{M} \\
V_{D}
\end{array}\right] \\
& v_{o}=C_{o n} \cdot x+D_{o n} \cdot u \rightarrow v_{o}=\left[\begin{array}{ll}
0 & R / R+R_{C}
\end{array}\right]\left[\begin{array}{l}
i_{L} \\
v_{C}
\end{array}\right]+\left[\begin{array}{lll}
0 & 0 & 0
\end{array}\right]\left[\begin{array}{l}
V_{G} \\
V_{M} \\
V_{D}
\end{array}\right]
\end{aligned}
$$

The equations of the converter when the switch is OFF:

$$
\begin{aligned}
\dot{x}=A_{o f f} \cdot x+ & B_{o f f} \cdot u \rightarrow\left[\begin{array}{l}
i_{L} \\
v_{C}
\end{array}\right] \\
& =\left[\begin{array}{cc}
-\left(R \cdot R_{L}+R \cdot R_{D}+R_{C} \cdot R_{L}+R_{C} \cdot R_{D}+R \cdot R_{C}\right) /\left(R+R_{C}\right) \cdot L & -R /\left(R+R_{C}\right) \cdot L \\
R & -1 /\left(R+R_{C}\right) C
\end{array}\right]\left[\begin{array}{l}
i_{L} \\
v_{C}
\end{array}\right] \\
& +\left[\begin{array}{ccc}
1 / L & 0 & -1 / L \\
0 & 0 & 0
\end{array}\right]\left[\begin{array}{l}
V_{G} \\
V_{M} \\
V_{D}
\end{array}\right] \\
v_{o}= & C_{o f f} \cdot x+D_{o f f} \cdot u \rightarrow v_{o}=\left[\begin{array}{ll}
\left.R \cdot R_{C} / R+R_{C}\right) \cdot L & R / R+R_{C}
\end{array}\right]\left[\begin{array}{l}
i_{L} \\
v_{C}
\end{array}\right]+\left[\begin{array}{lll}
0 & 0 & 0
\end{array}\right]\left[\begin{array}{c}
V_{G} \\
V_{M} \\
V_{D}
\end{array}\right]
\end{aligned}
$$

Entire system equations are calculated with duty cycle (D) according to on and off times (on time denoted by $\mathrm{D}$ and off time denoted by (1-D) :

$\dot{x}=\left(A_{o n} \cdot D+A_{o f f} \cdot(1-D)\right) \cdot x+\left(B_{o n} \cdot D+B_{o f f} \cdot(1-D)\right) \cdot u=A_{t} \cdot x+B_{t} \cdot u$

At the steady state, duty cycle is on its nominal value and state variables can be obtained at that equilibrium.

$\dot{x}=A_{t} \cdot x+B_{t} \cdot u=0 \rightarrow x=\left[\begin{array}{c}i_{L} \\ v_{C}\end{array}\right]=-A_{t}^{-1} \cdot B_{t} \cdot\left[\begin{array}{c}V_{G} \\ V_{M} \\ V_{D}\end{array}\right]$ 
Output voltage also can be calculated:

$v_{o}=\left(C_{o n} \cdot D+C_{o f f} \cdot(1-D)\right) \cdot x+\left(D_{o n} \cdot D+D_{o f f} \cdot(1-D)\right) \cdot u=C_{t} \cdot x+D_{t} \cdot u$

$v_{o}=\frac{\left(R+R_{C}\right) \cdot(1-D) \cdot R}{\Delta} \cdot V_{G}-\frac{\left(R+R_{C}\right) \cdot(1-D) \cdot D \cdot R}{\Delta} \cdot V_{M}-\frac{\left(R+R_{C}\right) \cdot(1-D)^{2} \cdot R}{\Delta} \cdot V_{D}$

$\Delta=\left(R_{L}+R_{M}\right) \cdot\left(R+R_{C}\right)+\left(R \cdot R_{C}+R \cdot R_{D}+R_{C} \cdot R_{D}-R \cdot R_{M}-R_{M} \cdot R_{C}\right) \cdot(1-D)+R^{2} \cdot(1-D)^{2}$

\section{Inverter}

When the generated power is transmitted to the grid, or used by AC loads, it is necessary to use DC-AC converters (inverters). Inverters can be single phase or three phase output. There are four common grid integrated inverters for photovoltaic systems: the central plant inverter system, the string inverter system, the multi-string inverter system, and microgrid inverter (AC modules) system. Central plant inverter is the past technology, and it is based on centralized inverters that interfaced a large number of PV modules to the grid. The PV modules are connected in series (called a string). These strings are connected in parallel with string diodes, in order to get high power levels. String inverters are the present technology, and they are the reduced type of the central plant inverter that each string connected to the inverter. Multi-string inverters have several strings, and they are connected with their own DC-DC converter to a common DC-AC inverter. String inverters are better than the central plant inverters because of their individual controllability. The AC module is a small version of the string inverter, where each PV module has its integrated power electronic interface to the grid [6]. Generally, central plant inverters are used in 1 to $5 \mathrm{~kW}$, string inverters are used in 0,5 to $1 \mathrm{~kW}$ and AC modules are used in 0,1 to 0,5 $\mathrm{kW}$ [2]. However, inverters which are used in smart grid must offer a number of different features such as bidirectional operation, high efficient power converters, measuring and controlling power flows with smart meters and communication, synchronization capabilities, electromagnetic interference (EMI) filtering. Three phase grid connected DC-AC inverter block diagram is given in Figure 3.

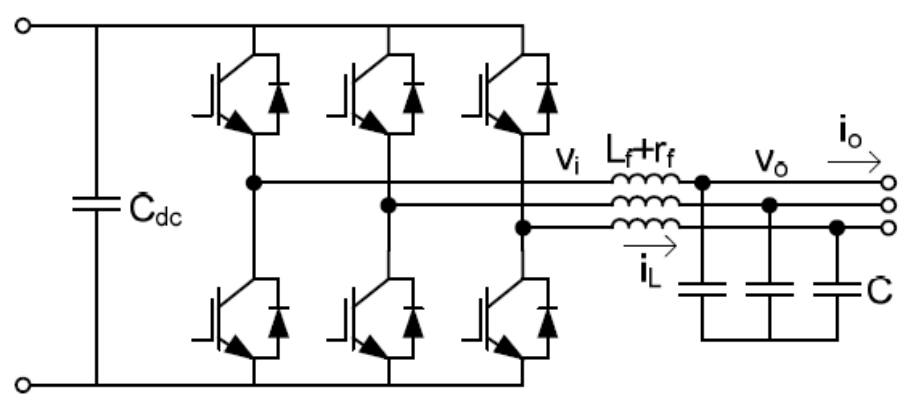

Fig. 3: Block diagram of three phase inverter.

Reference output voltage generation can be explained with 11 steps $[8,9]$.

Step 1: Figure 4 shows the flow chart of obtaining PLL phase angle using three phase output voltage.

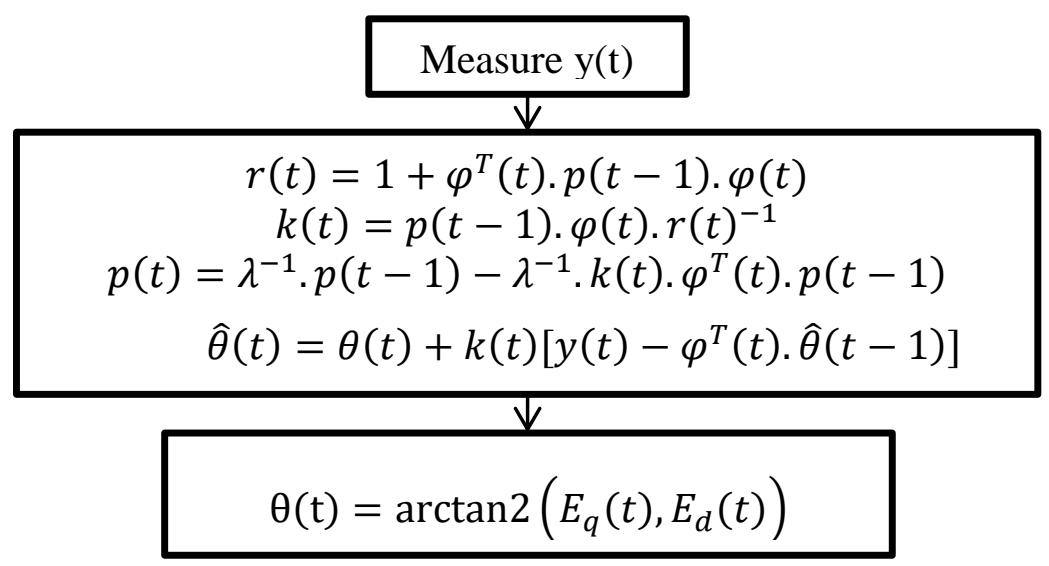

Fig. 4: Flow chart of PLL phase angle generation. 
Step 2: Clarke conversion for phase voltage

$$
\left[\begin{array}{l}
v_{\alpha, \text { in }} \\
v_{\beta, \text { in }}
\end{array}\right]=\frac{2}{3} \cdot\left[\begin{array}{ccc}
1 & \frac{1}{2} & -\frac{1}{2} \\
0 & \frac{\sqrt{3}}{2} & -\frac{\sqrt{3}}{2} \\
\frac{1}{2} & \frac{1}{2} & \frac{1}{2}
\end{array}\right] \cdot\left[\begin{array}{l}
v_{\text {phaseR }, \text { in }} \\
v_{\text {phases }, \text { in }} \\
v_{\text {phaseT }, \text { in }}
\end{array}\right]
$$

Step 3: Clarke conversion for angle calculation

$$
\left[\begin{array}{l}
v_{\alpha, P L L} \\
v_{\beta, P L L}
\end{array}\right]=\frac{2}{3} \cdot\left[\begin{array}{ccc}
1 & \frac{1}{2} & -\frac{1}{2} \\
0 & \frac{\sqrt{3}}{2} & -\frac{\sqrt{3}}{2} \\
\frac{1}{2} & \frac{1}{2} & \frac{1}{2}
\end{array}\right] \cdot\left[\begin{array}{l}
\text { RPLLE } \\
\text { SPLLE } \\
\text { TPLLE }
\end{array}\right]
$$

Step 4: Clarke conversion for phase current

$$
\left[\begin{array}{l}
i_{\alpha} \\
i_{\beta}
\end{array}\right]=\frac{2}{3} \cdot\left[\begin{array}{ccc}
1 & \frac{1}{2} & -\frac{1}{2} \\
0 & \frac{\sqrt{3}}{2} & -\frac{\sqrt{3}}{2} \\
\frac{1}{2} & \frac{1}{2} & \frac{1}{2}
\end{array}\right] \cdot\left[\begin{array}{l}
i_{\text {phaseR }, \text { in }} \\
i_{\text {phases, in }} \\
i_{\text {phaseT, in }}
\end{array}\right]
$$

Step 5: Park transformation for voltage and current

$$
\begin{aligned}
{\left[\begin{array}{l}
v_{d, \text { meas }} \\
v_{q, \text { meas }}
\end{array}\right] } & =\left[\begin{array}{cc}
\sin (\text { PLLteta }) & -\cos (\text { PLLteta }) \\
\cos (\text { PLteta }) & \sin (\text { PLLteta })
\end{array}\right] \cdot\left[\begin{array}{l}
v_{\alpha, \text { in }} \\
v_{\beta, \text { in }}
\end{array}\right] \\
{\left[\begin{array}{l}
i_{d, \text { meas }} \\
i_{q, \text { meas }}
\end{array}\right] } & =\left[\begin{array}{cc}
\sin (\text { PLteta }) & -\cos (\text { PLLteta }) \\
\cos (\text { PLteta }) & \sin (\text { PLLteta })
\end{array}\right] \cdot\left[\begin{array}{l}
i_{\alpha} \\
i_{\beta}
\end{array}\right]
\end{aligned}
$$

Step 6: Reference $i_{d}$ and $i_{q}$ calculation

$$
\begin{gathered}
v_{d c_{-} e r r}=v_{d c b u s_{-} \text {meas }}-v_{d c b u s_{-} r e f} \\
i_{d, r e f}=K_{p} \cdot v_{d c_{-} e r r}+\int K_{i} \cdot v_{d c_{-} e r r} \\
i_{q, \text { ref }}=0
\end{gathered}
$$


Step 7: Reference $v_{d}$ and $v_{q}$ calculation

$$
\begin{gathered}
v_{D_{-} e r r}=i_{d, r e f}-i_{d, \text { meas }} \\
v_{d, r e f}=K_{p} \cdot v_{D_{-} e r r}+\int K_{i} \cdot v_{D_{-} e r r} \\
v_{Q_{-} e r r}=i_{q, \text { ref }}-i_{q, \text { meas }} \\
v_{q, \text { ref }}=K_{p} \cdot v_{Q_{-} \text {err }}+\int K_{i} \cdot v_{Q_{-} e r r}
\end{gathered}
$$

Step 8: Current Regulator Feed Forward Value Calculation

$$
\begin{aligned}
& v_{\text {dFeFo }}=v_{\text {d,meas }}+\left(i_{d, \text { ref }} \cdot R\right)-\left(i_{\text {q,ref }} \cdot L\right) \\
& v_{\text {qFeFo }}=v_{q, \text { meas }}+\left(i_{d, \text { ref }} \cdot L\right)+\left(i_{q, \text { ref }} \cdot R\right)
\end{aligned}
$$

Step 9: Converter Reference dq axis calculation

$$
\begin{aligned}
& v_{d \text { ConRef }}=v_{d, \text { ref }}+v_{d F e F o} \\
& v_{\text {qConRef }}=v_{q, \text { ref }}+v_{\text {qFeFo }}
\end{aligned}
$$

Step 10: Reference U, V, W signal calculation and inverter pulse generation

$$
\begin{aligned}
& m=\frac{v_{d c b u s_{-} r e f} / 2}{v_{\text {trf_sec }} \cdot \sqrt{\frac{2}{3}}} \\
& \operatorname{Re}\left[v_{\text {ConRef }}\right]=v_{\text {dConRef }} / m \\
& \operatorname{Im}\left[v_{\text {ConRef }}\right]=\frac{v_{q \text { ConRef }}}{m} \\
& \operatorname{Mag}\left[v_{\text {ConRef }}\right]=\sqrt{\operatorname{Re}\left[v_{\text {ConRef }}\right]^{2}+\operatorname{Im}\left[v_{\text {ConRef }}\right]^{2}} \\
& \operatorname{Ang}\left[v_{\text {ConRef }}\right]=\arctan 2\left(\operatorname{Re}\left[v_{\text {ConRef }}\right], \operatorname{Im}\left[v_{\text {ConRef }}\right]\right) \\
& A n g_{\text {LegU }}=A n g\left[v_{\text {ConRef }}\right]+0+\text { PLLteta }-\frac{\pi}{6}+\left(T_{s} . f .2 \pi\right) \\
& A n g_{\text {LegV }}=A n g\left[v_{\text {ConRef }}\right]-\frac{2 \pi}{3}+\text { PLLteta }-\frac{\pi}{6}+\left(T_{s} . f .2 \pi\right) \\
& A n g_{\text {LegW }}=A n g\left[v_{\text {ConRef }}\right]+\frac{2 \pi}{3}+\text { PLLteta }-\frac{\pi}{6}+\left(T_{s} . f .2 \pi\right) \\
& R e f_{\text {LegU }}=\operatorname{Mag}\left[v_{\text {ConRef }}\right]+\sin \left(\text { Ang }_{\text {LegU }}\right) \\
& R e f_{\text {LegV }}=\operatorname{Mag}\left[v_{\text {ConRef }}\right]+\sin \left(A n g_{\text {LegV }}\right) \\
& R e f_{\text {LegW }}=\operatorname{Mag}\left[v_{\text {ConRef }}\right]+\sin \left(A n g_{\text {LegW }}\right)
\end{aligned}
$$

Step 11: PWM generation can be produced according to $R e f_{L e g U}, R e f_{\text {LegV }}$, and $R e f_{\text {LegW }}$. 


\section{Simulation Results}

The system simulated with Matlab Simulink. Model and control block are written as C codes using S-function feature. System parameters of the system are given in Table 1. Figure 5 shows system single phase output voltage and current waveforms. Figure 6 shows system three phase output voltage waveforms. Figure 7 shows system three phase output current waveforms.

Table 1: System simulation parameters.

\begin{tabular}{|c|c|}
\hline Output Power & $100 \mathrm{~kW}$ \\
\hline Output Phase to Phase Voltage & $260 \mathrm{~V}$ \\
\hline Output Filter Inductance & $250 \mathrm{uH}$ \\
\hline Resistance of Output Filter Inductance & $1.88 \mathrm{~m} \Omega$ \\
\hline Grid Frequency & $60 \mathrm{~Hz}$ \\
\hline DC Bus Voltage & $500 \mathrm{~V}$ \\
\hline DC Bus Capacitors & $5 \times 4800 \mathrm{uF}$ \\
\hline Switching Frequency & $20 \mathrm{kHz}$ \\
\hline
\end{tabular}

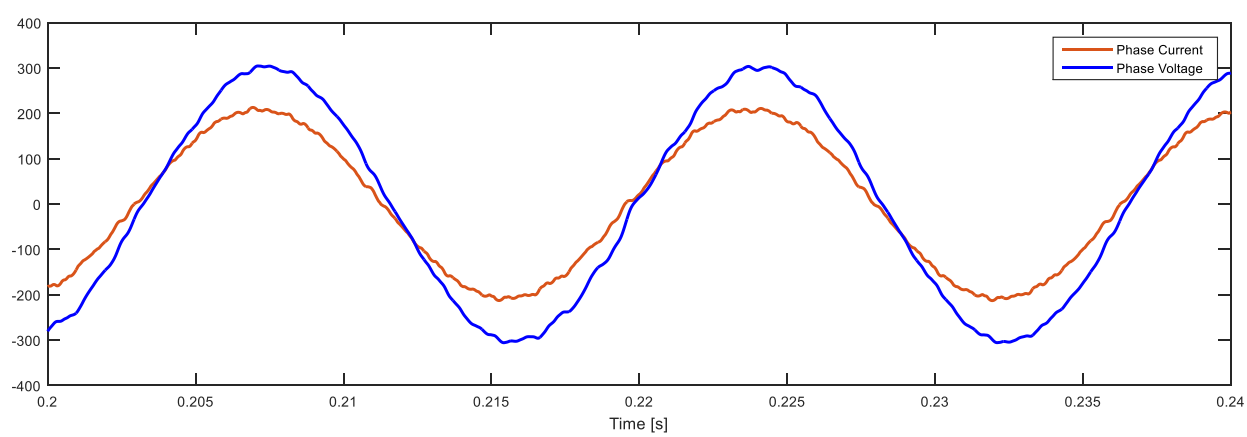

Fig. 5: Single phase voltage and current waveforms.

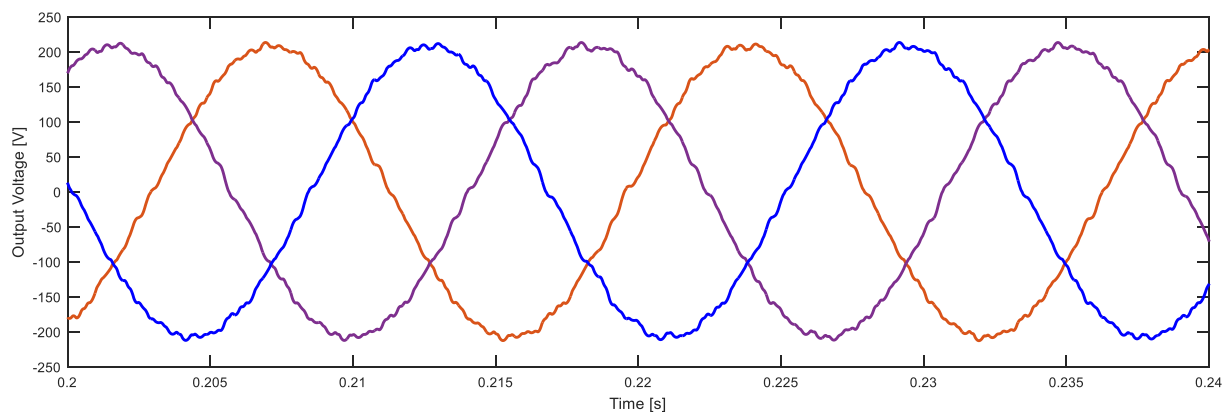

Fig. 6: Three phase voltage waveforms.

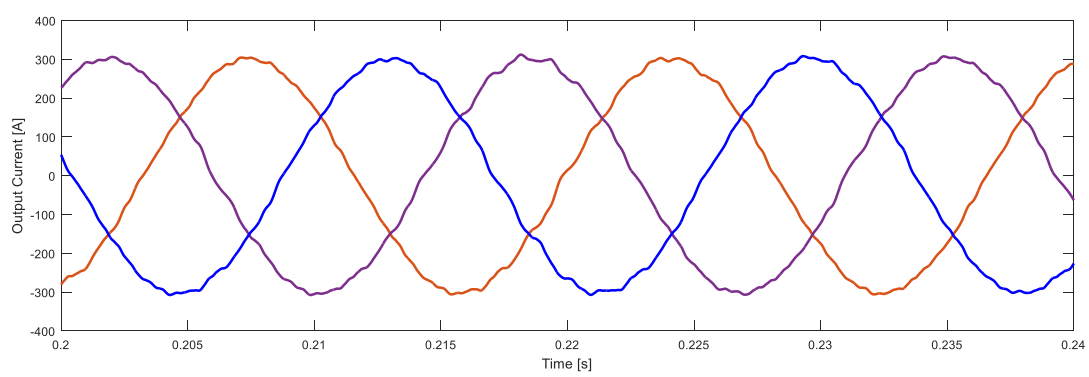

Fig. 7: Three phase current waveforms. 


\section{Conclusion}

In this paper, a $100 \mathrm{~kW}$ three phase grid connected photovoltaic system is examined and simulated in Matlab with using system function feature. Detailed mathematical equations of the system parts are given. These equations are written in $\mathrm{S}$-function with $\mathrm{C}$ codes. Thus, a simulation model that is general and applicable in embedded systems is achieved. Codes will be used in laboratory scale implementation of the system as future work.

\section{References}

[1] G. Bhuvaneswari and R. Annamalai, "Development of a solar cell model in Matlab for PV based generation systems," in Proceedings of the IEEE Annual India Conference, pp. 1-5.

[2] F. Blaabjerg, Z. Chen, and S. B. Kjaer, "Power electronics as efficient interface in dispersed power generation systems," IEEE Transactions on Power Electronics, vol. 19, no. 5, pp. 1184-1194, 2004.

[3] M. G. Villalva, J. R. Gazoli, and E. R. Filho, "Comprehensive approach to modeling and simulation of photovoltaic arrays," IEEE Transactions of Power Electronics, vol. 24, no. 5, pp. 1198-1208, 2009.

[4] T. Salmi, M. Bouzguenda, A. Gastli, and A. Masmoudi, "Matlab/Simulink based modelling of solar photovoltaic cell," International Journal of Renewable Energy Research, vol. 2, no, 2, pp. 213-218, 2012.

[5] N. Mohan, T. M. Undeland, and W. P. Robbins, Power Electronics, Converters, Applications, and Design. John Wiley \& Sons, 2003.

[6] D. Rekioua and E. Matagne, "Power electronics modeling," in Optimization of Photovoltaic Power Systems Modelization, Simulation and Control, Springer, Verlag, London, 2012, pp. 89-112.

[7] M. R. Modabbernia, A. R. Sahab, M. T. Mirzaee, and K. Ghorbany, "The state space average model of boost switching regulator including all of the system uncertainties," Advanced Materials Research, vol. 403-408, pp. 3476-3483, 2012.

[8] A. Paquette, "Power quality and inverter-generator interactions in microgrids," Ph.D. dissertation, The School of Electrical and Computer Engineering, Georgia Institute of Technology, 2014.

[9] M. Kahraman, "Mikroişlemci tabanlı faz kilitleme uygulaması," Master Thesis, Dep. Elect. Eng., Gazi University, Ankara, Turkey, 2005. 